\title{
DIRECTIONS FOR MANAGEMENT IN SMALL AND MEDIUM HOTELS AND RESTAURANTS COMPANIES
}

\author{
Ana LUCAS* \\ Universidade Europeia, Faculdade de Ciências Sociais e Tecnologia, Lisboa, Portugal; CiTUR Centre for \\ Tourism Research, Development and Innovation, Polytechnic of Leiria, Leiria, Portugal, e-mail: a_lucas@ sapo.pt
}

Ana RAMIRES

Universidade Europeia, Faculdade de Ciências Sociais e Tecnologia, Lisboa, Portugal, e-mail: anaramires.ps@gmail.com

\begin{abstract}
Citation: Lucas, A., \& Ramires, A. (2022). DIRECTIONS FOR MANAGEMENT IN SMALL AND MEDIUM HOTELS AND RESTAURANTS COMPANIES. GeoJournal of Tourism and Geosites, 40(1), 210-217. https://doi.org/10.30892/gtg.40125-821
\end{abstract}

\begin{abstract}
The primary goal is to validate if there is a relationship between liquidity and economic profitability in hotels and restaurants sectors, in small and medium companies (SMCs). The question to be answered is whether the short-term view will not compromise the future results of those companies. After a literature review, hotels and restaurants financial ratios were analysed over 5 years. Data were also treated using linear regression, to understand if there is a relation between liquidity and economic profitability. All the financial information was obtained from the SABI database. According to the studied literature, it was not expected to have any relationship between liquidity and economic profitability. The study consists of the Portuguese context in the latest 5 years period before COVID-19, in the hotels and restaurants sector, and it does validate those previous studies. Indeed, findings show no relationship between both ratios. Findings show to hotels and restaurants managers that liquidity-based management does not necessarily lead to future economic profitability. Even if liquidity is necessary for accurate short-term management, it shall not be used to guide them in the decision-making process concerning economic profitability. The results obtained are of enormous importance to both practitioners and academics. Managers must understand that they must take into account the need for liquidity in a short-term vision, but they must also understand that this fact alone is not a guarantee of good profitability in a long-term vision. The results in the empirical study also help to reinforce the inexistence of a relationship between the liquidity ratio and the economic profitability ratio in the literature.
\end{abstract}

Key words: economic profitability, hotels management, liquidity ratio, Portugal, restaurants management

$* \quad * \quad * \quad * \quad * \quad *$

\section{INTRODUCTION}

Tourism is an important source of income for all 28 countries in Europe. The weight that these revenues represent in the Gross Domestic Product (GDP) of each country is variable. In Portugal, tourism revenues in 2019 accounted for around $8.5 \%$ of GDP, and it has been growing steadily in recent years, before the COVID-19 pandemic (FFMS, 2020a). Employment in the tourism sector, in that year, represented $6.5 \%$ of employment in the national economy (Turismo de Portugal, 2020). The weight of tourism revenues in GDP reflects the importance that this sector has for the economy of a country. Two of the sectors that directly influence this weight of tourism revenues are restaurants and accommodation. The management of these business units has suffered a severe setback since the beginning of the global pandemic due to COVID-19, which has led to drastic reductions in the profitability of companies in those sectors. Also, the main Portuguese business structure is of small and medium companies (SMCs), and these sectors are no exception. One of the characteristics of these companies is the fact that the operational management is mostly based on the analysis of liquidity (Atrill and McLaney, 2019; Bordeianu and Radu, 2020; Nikolaos et al., 2020), instead of the accounting results. The main objective of this article is to validate, or not, the relationship between liquidity and economic profitability (Atrill and McLaney, 2019; Bordeianu and Radu, 2020) in each of these sectors, in SMCs. Therefore, the research question is: "Does a higher liquidity leads to higher economic profitability, in the hotels and restaurants sector held by SMCs?"

Hence, it is intended to understand whether liquidity actually leads to subsequent positive net results. In crises, such as was experienced during COVID-19, management tends to be based even more on the short term, that is, on a more treasury perspective, than on the medium and long term, from an economic perspective. Accordingly, the question to be answered is whether this short-term view will not compromise the future results of those SMCs. Therefore, the objectives of the investigation are: (1) to analyze the evolution of the liquidity of hotels and restaurants in the last 5 years before COVID-19; (2) to analyze the evolution of the economic profitability of hotels and restaurants in the last 5 years before COVID-19; (3) to analyze the overall financial performance of SMCs hotels and restaurants; and (4) to analyze the relationship between liquidity and economic profitability, if existing. To answer the research question and to achieve the proposed goals, a previous literature review was realized focusing on the concepts of liquidity, economic profitability, and SMCs management. Portuguese hotels and restaurants' financial ratios, liquidity, and economic

* Corresponding author 
profitability were analyzed in five years, from 2015 to 2019. All the information was obtained from The Iberian Balance Sheet Analysis System (SABI) from Bureau van Dijk (2021), a database of detailed financial information of Portuguese and Spanish companies. The search included only Portuguese hotels and restaurants, detained by SMCs. To achieve the first, second, and third objectives, it was done a simple statistical analysis, to gauge the evolution over the 5 years under analysis, based on its average values. This evolution is presented by groups, hotels, and restaurants, and graphically, to make the evolution more noticeable. The analysis is done separately for liquidity and economic profitability.

Then, for the fourth goal, data were treated using linear regression. This linear regression made it possible to understand if there is a relation between liquidity and economic profitability in those companies. According to the studied literature, it was expected no relationship between liquidity and economic profitability. Indeed, findings point to the fact that liquidity-based management does not necessarily lead to future economic profitability, and in the long-term running, managers should review the management tools they use to guide them in the decision-making process. Findings also open doors to further empirical studies, to investigate this issue in more depth and with data directly obtained from the SMCs. In terms of structure, the study adopts a conventional format: literature review; explanation of the methodology; presentation of findings; and discussion and conclusions.

\section{Tourism impact on the Portuguese economy}

Tourism is a traditional and fundamental sector of the Portuguese economy. In recent years, before COVID-19, it has shown high growth in its main indicators: contribution to GDP, supply of several beds, employment, and average daily expenses per tourist. According to FFMS (2020a), the weight of the tourism sector has been increasing gradually, but consistently, in Portuguese GDP, over the last years, before the beginning of the global pandemic, in 2020 (Figure 1). The expected value in 2020 is $3,8 \%$, well below the trend of recent years.

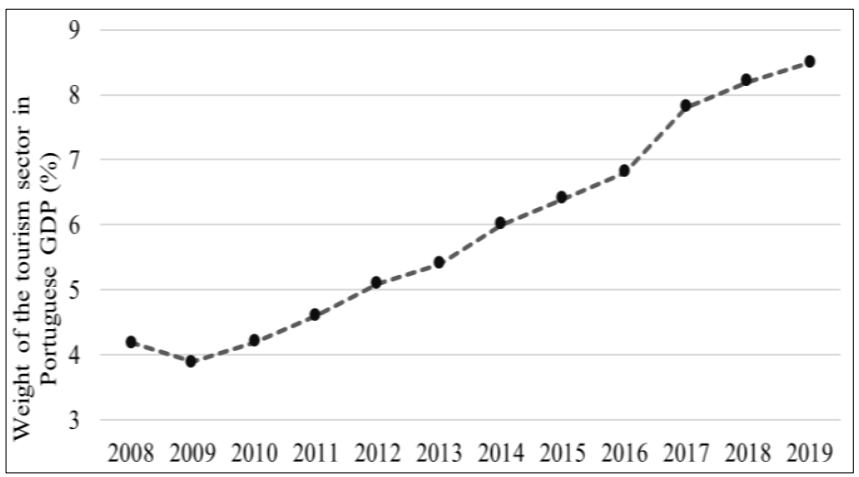

Figure 1. Weight of the tourism sector in Portuguese GDP (Source: FFMS, 2020a)

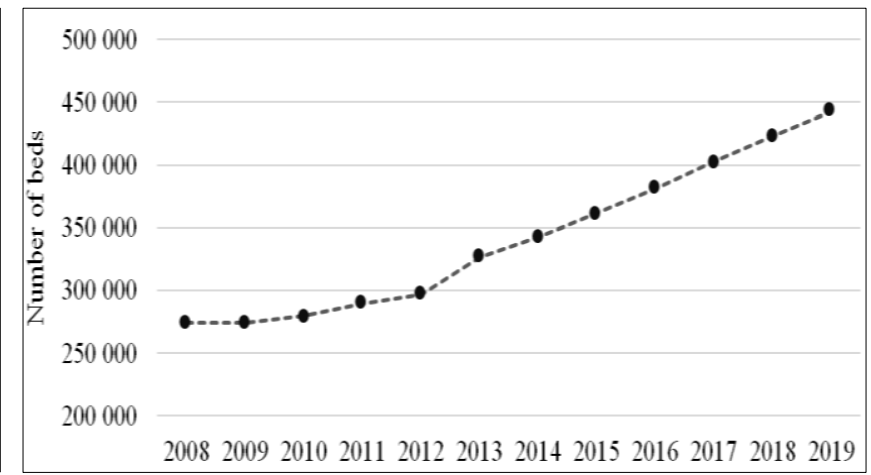

Figure 2. Number of beds available in hotel establishments (Source: FFMS, 2020b)

The number of beds available in tourist establishments has also been increasing exponentially (Figure 2), before the COVID-19 pandemic, according to FFMS (2020b). This increase is justified by the increase both in demand and in income per tourist that has occurred in recent years. However, with the emergence of the global pandemic and the consequent confinement that existed in Portugal, the number of tourist establishments with activity suspension reached from 109 in February up to 965 in April, representing 21.28\% of the total of those tourist establishments (Turismo de Portugal, 2021a).

Employment in the tourism sector has also been increasing its share of total employment in Portugal, in the last years before the global pandemic. The evolution in recent years, based on INE (2019), can be analyzed in Figure 3. The number of jobs also expectably decreased by $8.9 \%$ in 2020 (Turismo de Portugal, 2021b).

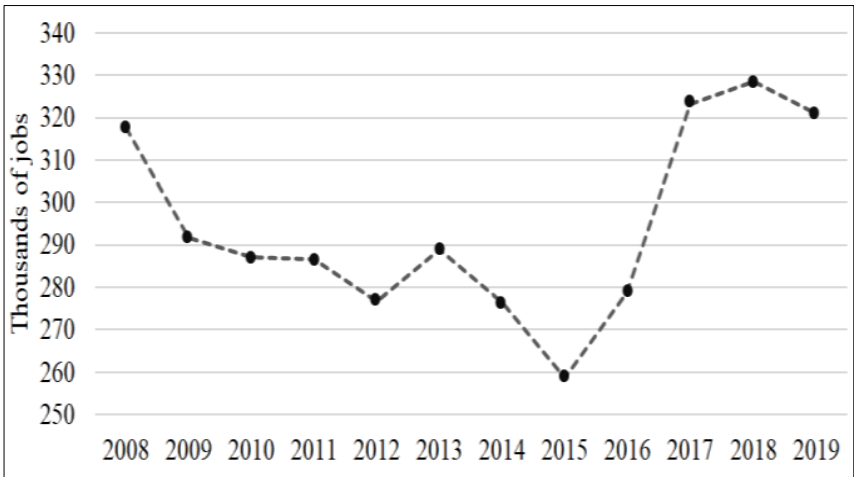

Figure 3. Total employment in tourism (Source: INE, 2019)

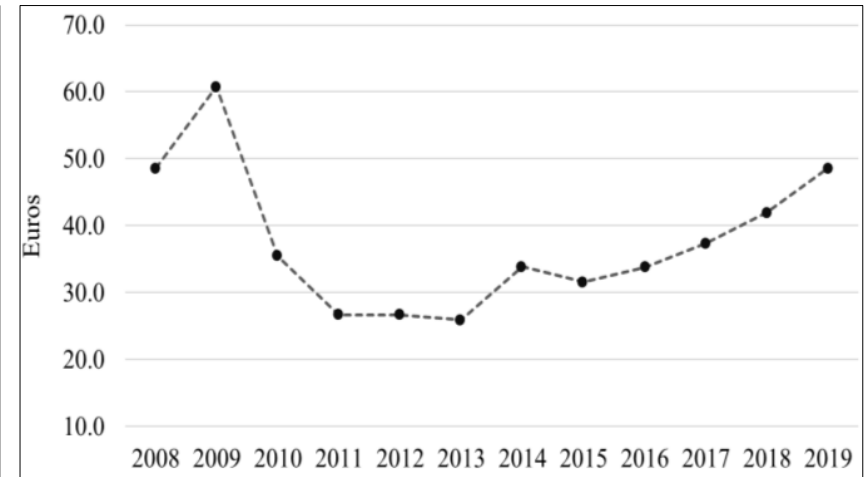

Figure 4. Average daily expenditure per tourist (Source: FFMS, 2020c)

Finally, according to FFMS (2020c), the average daily expenditure per tourist (Figure 4) had its highest value in 2009, followed by a significant decrease in the following years. However, since 2013 it has increased again, although slightly. In 
2020, the average value of daily expenses reached a predictable value of $€ 57.69$ (Turismo de Portugal, 2021c), increasing slightly compared to previous years. However, the pandemic COVID-19 and the restrictive measures adopted by the government determined a sharp drop-in tourism activity, which led to a decrease of $61.3 \%$ in guests, so the increase in the value of average daily expenses was not enough to maintain global tourism revenues from previous years.

In short, although all the indicators presented, between 2008 and 2019, are in a positive evolution, the forecasts of the same indicators for 2020 are well below this trend, because of the global pandemic due to COVID-19.

\section{Small and medium companies' management}

Academic research has mainly focused on large companies listed in financial markets, mainly due to the data availability. However, in more recent years, new databases with detailed business information on micro, small and medium-sized enterprises have appeared, allowing the analysis of time series (Espert et al., 2012). The SMCs definition can be defined as all private enterprises, excluding agriculture, hunting, and fishing, employing less than 250 employees. National definitions may exist (Reyes-Ruiz and Hernández-Hernández, 2020), however, it is common to distinguish the following sizes: micro-enterprises, with less than 10 employees; small enterprises, with 10 to 49 employees; and mediumsized enterprises, with 50 to 249 employees (Verheul et al., 2001). In Portugal, there were 1,281,857 micros, 44,492 small, and 7,300 medium-sized companies in 2019, which accounted for $99.90 \%$ of the total business companies.

Of those companies, 117,971 were from the hotels and restaurants sector (FFMS, 2021). Additionally, SMCs have a very important performance in any current economy, as they contribute both to the generation of wealth and the creation of jobs (Reyes-Ruiz and Hernández-Hernández, 2020). Many managers of SMCs have the professional knowledge directly related to their activity, however not necessarily the management and economical knowledge (De Vries et al., 2009; Lakatos, 2020; Reyes-Ruiz and Hernández-Hernández, 2020). The competitiveness of SMCs depends to a large extent on their growth and expansion capacity (Espert et al., 2012). However, when they need financing investment projects, SMCs only use internal financing and bank loans. Small businesses, even to finance their operations, have little internal cash flow, and in these cases, they also need bank loans. But to loan to SMCs, banks look for their future financial and economic profitability (Paulet et al., 2014). Though SMCs managers tend to have a short-term view of their business (De Vries et al., 2009) and managers generally rate their business success with a cash flow approach, meaning, they are mostly concerned with whether their company's liquidity is good or not (Lakatos, 2020). This sort of management based on the short term and the analysis of liquidity can thus be an obstacle to improving the growth and expansion capacity of SMCs.

\section{Liquidity ratios}

A financial ratio generally defines the relationship between two numbers. Those numbers are usually based on the Balance Sheet and/or the Statement of Profit and Loss. These financial ratios provide important information to strengthen the decision-making (Reyes-Ruiz and Hernández-Hernández, 2020; Rondós-Casas et al., 2018). They are powerful tools to help summarize financial statements and the health of a company or enterprise (Bordeianu and Radu, 2020).

Rondós-Casas et al. (2018) also claim that ratios are a tool used by both scholars in their research and professionals in the study of a company or a sector. The same study also states that ratios provide more information when compared to the historical values for the same company, or sector. Ratios that focus the study of the short-term financial information include net working capital (Bhattacharyya and Jagadeesh, 2018; Lakatos, 2020), current liquidity ratio (Bordeianu and Radu, 2020; Nikolaos et al., 2020), quick liquidity ratio (Atrill and McLaney, 2019; Bordeianu and Radu, 2020; Nikolaos et al., 2020), and cash liquidity ratio (Bordeianu and Radu, 2020; Nikolaos et al., 2020), among others (Table 1).

Table 1. Liquidity ratios

\begin{tabular}{|l|l|l|}
\hline Ratio & Formula & Source \\
\hline Networking capital & Current assets - Current liabilities & Bhattacharyya and Jagadeesh (2018); Lakatos (2020) \\
\hline Current Liquidity Ratio & Current Assets / Current Liabilities & Bordeianu and Radu (2020); Nikolaos et al. (2020) \\
\hline Quick Liquidity Ratio & (Current Assets - Inventories) / Current Liabilities & $\begin{array}{l}\text { Atrill and McLaney (2017); Bordeianu and Radu (2020); } \\
\text { Nikolaos et al. (2020) }\end{array}$ \\
\hline Cash Liquidity Ratio & (Cash + Cash equivalents) / Current Liabilities & Bordeianu and Radu (2020); Nikolaos et al. (2020) \\
\hline
\end{tabular}

Networking capital management is an important way in achieving profitability for micro, small and medium enterprises (Bhattacharyya and Jagadeesh, 2018). It is the difference between a company's current assets, such as cash, accounts receivable, and inventories, and its current liabilities, such as accounts payable. This indicator is also a form of measuring the company's liquidity. Its basic goal is to make sure that a company has enough funds to meet its operating costs (Sagner, 2010). Companies focus on networking capital management to liberate funds and optimize liquidity.

Liquidity is defined by Papadeas and Sykianakis (2017) as the ability of an economic entity to repay its obligations without disrupting its proper functioning. The liquidity focus is on the short-term. Liquidity ratios examine the relationship between liquid resources held and payables due for payment shortly (Atrill and McLaney, 2019). Liquidity is considered in different studies in different forms. Some studies consider liquidity ratios, as current (Bordeianu and Radu, 2020; Nikolaos et al., 2020), quick (Atrill and McLaney, 2019; Bordeianu and Radu, 2020; Nikolaos et al., 2020), or cash liquidity ratios (Bordeianu and Radu, 2020; Nikolaos et al., 2020). Others consider liquidity as a cash flow approach, as the networking capital (Bhattacharyya and Jagadeesh, 2018; Lakatos, 2020). As SMCs managers generally evaluate their business success with a cash flow approach, they use to have practical knowledge of the liquidity indicators (Lakatos, 2020). 
This study will use the current liquidity ratio, as Bordeianu and Radu (2020) refers to it as the most common liquidity ratio and it indicates a company's ability to pay its short-term bills. Prior literature on restaurants and hotels liquidity ratio conclude that hotels have higher liquidity when compared to restaurants (Turegun, 2019).

\section{Economic profitability ratio}

Profitability ratios indicate a company's ability to generate earnings against cost during a given period. They are generally used to determine how profitable a company, or sector, is in sequential periods. Companies use various profitability ratios to provide useful insights into the financial well-being and performance of the business (Bordeianu and Radu, 2020). The economic profitability rates are an important instrument of financial analysis, as they reflect the level of the economic viability of a company (Burja and Burja, 2009).

Table 2 presents some of the most used profitability ratios, such as gross profit margin (Bordeianu and Radu, 2020; Van et al., 2021), net profit margin (Bordeianu and Radu, 2020; Lima Santos et al., 2021; Van et al., 2021), operating profit margin (Van et al., 2021), return on assets (ROA) (Bordeianu and Radu, 2020; Burja and Burja, 2009; Van et al., 2021), return on equity (ROE) (Bordeianu and Radu, 2020; Lima Santos et al., 2021; Van et al., 2021), among others.

Table 2. Profitability ratios

\begin{tabular}{|l|l|l|}
\hline Ratio & Formula & Source \\
\hline Gross Profit Margin & Gross profit / Sales revenue & Bordeianu and Radu (2020); Kamanduliené and Kulbokas (2020) \\
\hline Net Profit Margin & Net income / Total sales & Bordeianu and Radu (2020); Lima Santos et al. (2021) \\
\hline Operating Profit Margin & $\begin{array}{l}\text { Revenue - Expenses (excluding interest, taxes, } \\
\text { depreciation, and amortization) }\end{array}$ & Lukic (2018) \\
\hline Return on Assets & Profit / Total Assets & Bordeianu and Radu (2020); Burja and Burja (2009) \\
\hline Return on Equity & Net income / Equity & Bordeianu and Radu (2020; Lima Santos et al. (2021) \\
\hline
\end{tabular}

Gross profit margin measures how much is left after subtracting the cost of goods sold from revenue expressed in percentages (Kamandulienė and Kulbokas, 2020). Net profit margin shows the percentage of each remaining dollar sale after all costs and expenses, including interest, taxes, and preferred stock dividends, have been reduced (Bordeianu and Radu, 2020; Mulyadi et al., 2020). Operating profit margin measures how much profit a company makes on sales before paying interest or tax (Nguyen et al., 2019). It is a measure of the long-term performance of companies (Lukic, 2018). ROA indicates the effectiveness of using the assets to generate income, and the higher the value of ROA, the higher the efficiency of asset use (Bordeianu and Radu, 2020; Burja and Burja, 2009; Nguyen et al., 2019).

At last, ROE expresses the percentage of net income relative to stockholders' equity or the rate of return on the money that equity investors have put into the business (Bordeianu and Radu, 2020) The higher the ROE number, the higher the business financial performance (Nguyen et al., 2019). According to Bordeianu and Radu (2020), the ROA ratio specifically reveals how much after-tax profit a company generates for every one dollar of its assets. In financial literature, it is known as ROA (Burja and Burja, 2009). For these reasons, ROA is the ratio used in this study for the economic profit evaluation. Prior literature on micro, small and medium enterprises concluded that those companies performed favorably in liquidity, but had a low level of profitability.

Also, there was found no relationship between liquidity and profitability (Mendoza, 2015). Other studies, using ROE for economic profitability, concluded that restaurants have higher profitability than hotels (Turegun, 2019).

\section{MATERIALS AND METHODS}

This research uses secondary data from the SABI database (Bureau Van Dijk, 2021). Financial information was analyzed over the 5 years pre COVID-19, from 2014 to 2019, on Portuguese hotels and restaurants, detained by SMCs. The analysis of tourism companies was carried out separately in hotels and restaurants. The first group includes hotel establishments, vacation homes, and other short-term accommodation. The second one includes restaurants, mobile catering activities, provision of meals for events and other meal service activities, and beverage establishments. Inclusion factors were SMCs with activity, constituted before January 1st, 2015, from all

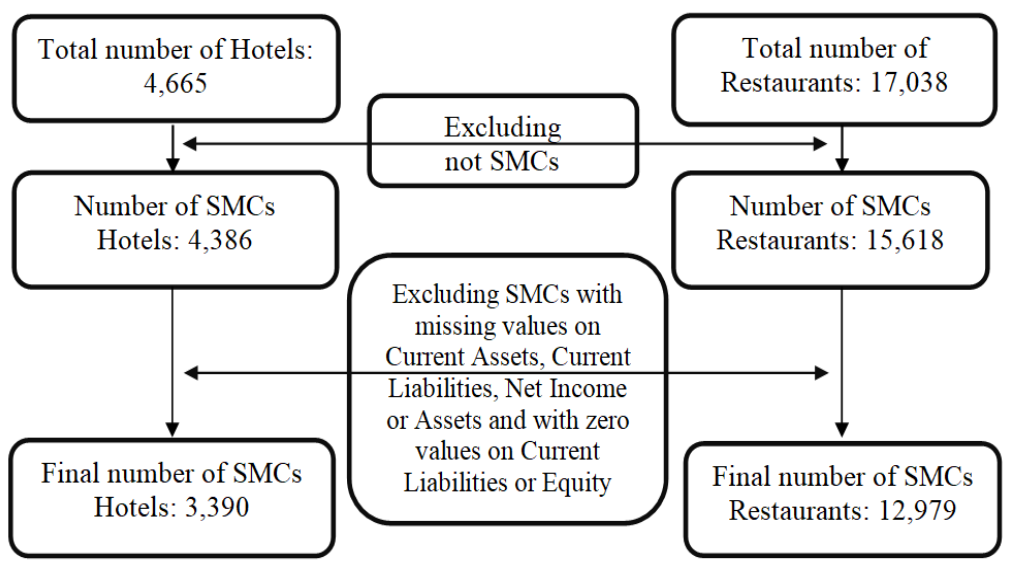

Figure 5. Selection of data process (Source: Self-development) regions from Portugal, including North Portugal, Portugal Center, Lisbon, and Tagus Valley, Alentejo, Algarve, Autonomous Region of the Azores, and Autonomous Region of Madeira, using the Nomenclature of Territorial Units for Statistics (NUTS) 2 Portuguese notation. Exclusion factors were not being an SMC, meaning having more than 249 workers, and having no employees declared; having no available values for current assets, current liabilities, or net income, as the financial ratios used in the study are based on those values; and also having a zero value for current 
liabilities or assets, as it would similarly be impossible to obtain the values of the ratios. Figure 5 shows the selection process of the data. Lastly, the study used the 5 years of a total of 3,390 hotels (68\% micro, 24\% small, and $8 \%$ medium-sized) and 12,979 restaurants (76\% micro, $22 \%$ small, and $2 \%$ medium-sized).

The study has as a main research question: "Does a higher liquidity leads to higher economic profitability, in the hotels and restaurants sector held by SMCs?". To answer the question, it was analyzed: (1) the evolution of the liquidity and economic profitability of hotels and restaurants in the last 5 years before COVID-19; (2) the overall financial performance of SMCs hotels and restaurants; and (3) the relationship between the liquidity and economic profitability in each of those groups. To accomplish the goals and to answer the research question, was done a study on financial ratios, current liquidity ratio, and ROA, based on financial information obtained from the SABI database (Bureau Van Dijk, 2021).

The analysis of financial information was divided into three stages: 1) the analysis of the evolution of Portuguese hotels and restaurants' financial ratios, namely current liquidity ratio, and ROA, in five years, from 2015 to 2019; 2) an overall analysis of these ratios; and 3) the analysis of the existence of any relationship between these two indicators in those sectors, through multiple linear regression.

To do an overall analysis of the ratios in the study, it was used the qualitative rating scale of Mendoza (2015) concerned liquidity and economic profitability (Table 3). This table shows the qualitative rating scale used in assessing the financial performance of the business enterprises, and it classifies into low, medium, and high for each measure. According to that study, the criteria were based on the experience of most enterprises. Those values are also following the literature on financial ratios (Atrill and McLaney, 2019; Bordeianu and Radu, 2020; Burja and Burja, 2009; Nikolaos et al., 2020).

Findings and analysis

The results are presented in four parts: liquidity evolution in the hotels and restaurants sector, economic profitability in the same sectors, an overall analysis of the financial ratios, and the relationship between economic liquidity and profitability, also in both sectors. SPSS version 28.0 was used to analyze the data. Before the analysis, companies with standardized values of liquidity or ROA outside the absolute value of 4 , the threshold score suggested for samples larger than 80 by Hair, et al. (2014), were marked as univariate outliers and removed, leading to a total of 3,328 hotels and 12,728 restaurants with valid data.

\section{Liquidity evolution}

The liquidity degree was measured using the current liquidity ratio, as it is generally done in similar studies (Atrill and McLaney, 2019; Bhattacharyya and Jagadeesh, 2018; Bordeianu and Radu, 2020; Nikolaos et al., 2020). Liquidity presents differently in hotels and restaurants. Both sectors have positive liquidity, on average, however, hotels liquidity tends to be higher than restaurants' (Figure 6). In both sectors, there is a large dispersion in the average liquidity of companies, as can be seen in Table 4. In hotels, the year 2016 had a high average score, more than twice as high as in other years. The application of the paired-samples t-test did not highlight statistically significant differences in the evolution of the current liquidity ratio across time (Table 5). Therefore, the liquidity mean was relatively stable, presenting values between 14 and 35 , a good average of approximately 19 , having the ability to meet short-term obligations with no difficulty. Restaurants are more stable yet show much lesser liquidity. Their average values are from 3 to 4 and on average around 4, and they also can pay short-term obligations. Only the increase observed in this sector from 2015 to 2016 was statistically significant (Table 5).

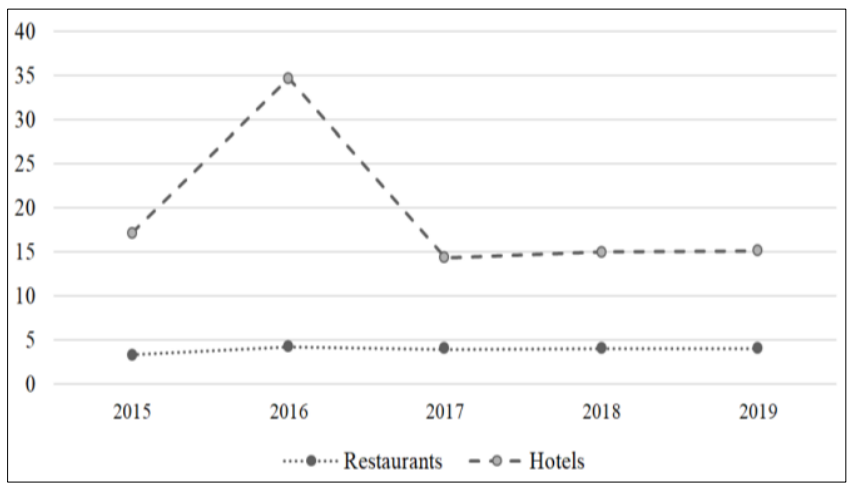

Figure 6. Liquidity evolution

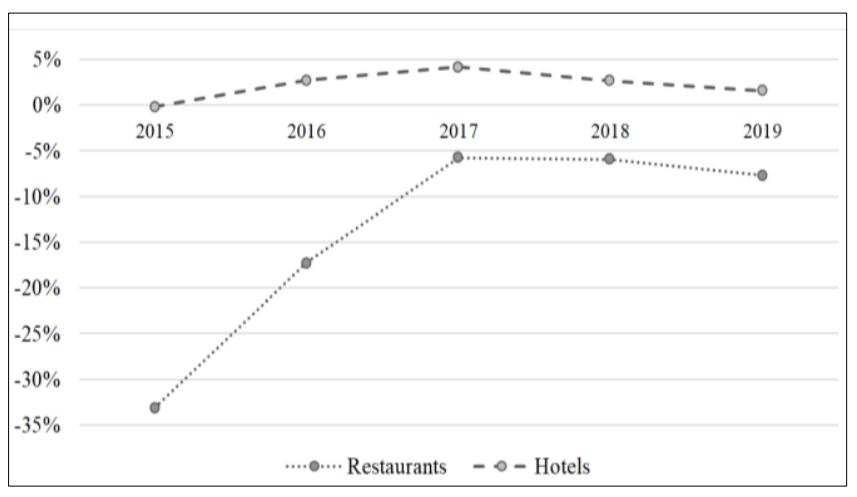

Figure 7. Economic Profitability (ROA) evolution

\section{Economic profitability evolution}

As Rondós-Casas et al. (2018) state that ratios provide more information when compared the historical values for the same company, or for the sector to which the company belongs, this study also analyses the evolution of the economic profitability during the five years pre COVID-19. Also, the economic profitability rate is an indicator that expresses the efficiency of using the equity of a firm (Burja and Burja, 2009), and the ROA ratio specifically reveals how much aftertax profit a company generates for every one dollar of its assets (Bordeianu and Radu, 2020). Similarly to liquidity, economic profitability was also studied based on the average of companies' values. Restaurants seem to have a highly variable economic profitability from year to year, being in general higher than the hotels. Hotels tend to have more 
stable profitability, but very low over the years (Figure 7). The analysis of the Table 4 allows us to verify that in this ratio there is also a great dispersion of the values towards the average. In both groups, the same pattern of evolution was observed: until 2017 the average value of ROA ratio increased followed by a gradual decrease.

However, over the 5 years, hotels showed in general positive mean scores and on average around $2 \%$, and restaurants negative ones with a 5-years mean of $-14 \%$. In 2015, the restaurants ROA ratio was at a very low negative level, but in the next two years, the increase was very prominent, growing approximately $50 \%$ and $33 \%$. Comparing the evolution of the ROA ratio across time, the results of the paired-samples t-test allowed us to conclude that almost all differences, increases and decreases between consecutive years, were statistically significant for both sectors. Only between 2017 and 2018, there was no difference between the means of the restaurants' economic profitability rates (Table 5).

\section{Overall analysis of the financial ratios}

The liquidity level and the economic profitability were also analyzed through the qualitative rating scale of Mendoza (2015). These rating results shown in Table 4, allow us to better understand the differences between the financial ratios of the hotels and restaurants. It confirms as seen before, that hotels have high liquidity, but restaurants only have a moderate one.

As for the ROA, the situation is similar, as both hotels and restaurants have a low level of economic profitability, although positive in the former and negative in the latter.
Table 4. Descriptive statistics (mean and standard deviation) and overall financial performance of SMCs hotels $(\mathrm{N}=3,328)$ and restaurants $(\mathrm{N}=12,728)$

\begin{tabular}{|c|c|c|c|c|}
\hline \multirow{2}{*}{ Year } & \multicolumn{2}{|c|}{ Current liquidity ratio } & \multicolumn{2}{c|}{ Return on Assets (\%) } \\
\cline { 2 - 5 } & Hotels & Restaurants & Hotels & Restaurants \\
\hline 2015 & $17.14(255.06)$ & $3.30(10.7)$ & $-0.18(26.70)$ & $-33.09(101.08)$ \\
\hline 2016 & $34.69(1,283.23)$ & $4.25(21.94)$ & $2.74(16.86)$ & $-17.23(74.23)$ \\
\hline 2017 & $14.29(132.24)$ & $3.93(9.37)$ & $4.13(18.36)$ & $-5.79(66.35)$ \\
\hline 2018 & $15.04(154.84)$ & $3.98(9.34)$ & $2.62(16.35)$ & $-6.00(65.87)$ \\
\hline 2019 & $15.08(170.71)$ & $3.98(8.85)$ & $1.51(18.65)$ & $-7.71(66.80)$ \\
\hline 5 -years & $19.25(277.50)$ & $3.89(8.49)$ & $2.16(12.71)$ & $-13.96(55.64)$ \\
\hline $\begin{array}{c}\text { Qualitative } \\
\text { Rating }\end{array}$ & High & Medium & Low & Low \\
\hline
\end{tabular}

Table 5. Comparison of the average of the ratios of SMCs hotels and restaurants across time

\begin{tabular}{|l|l|c|c|c|c|c|}
\hline Sector & Ratio & Comparison & Mean (SD) difference & $95 \%$ CI & $t$ & $p$-value \\
\hline Hotels & Current liquidity ratio & $2019-2018$ & $0.04(140.7)$ & $(-4.741,4.823)$ & 0.02 & .987 \\
\hline & & $2018-2017$ & $0.75(161.79)$ & $(-4.753,6.244)$ & 0.27 & .790 \\
\hline & & $2017-2016$ & $-20.40(1,277.08)$ & $(-63.804,23.005)$ & -0.92 & .357 \\
\hline & & $2016-2015$ & $17.56(1,302.25)$ & $(-26.703,61.816)$ & 0.78 & .437 \\
\hline & Return on Assets (\%) & $2019-2018$ & $-1.11(19.14)$ & $(-1.763,-0.463)$ & -3.35 & .001 \\
\hline & & $2018-2017$ & $-1.50(18.89)$ & $(-2.146,-0.862)$ & -4.59 & $<.001$ \\
\hline & & $2017-2016$ & $1.39(19.2)$ & $(0.739,2.044)$ & 4.18 & $<.001$ \\
\hline & & $2016-2015$ & $2.92(25.77)$ & $(2.042,3.794)$ & 6.53 & $<.001$ \\
\hline & & $2019-2018$ & $0.00(8.13)$ & $(-0.142,0.14)$ & -0.02 & .987 \\
\hline & & $2018-2017$ & $0.05(8.32)$ & $(-0.092,0.197)$ & 0.71 & .477 \\
\hline & & $2017-2016$ & $-0.32(20.86)$ & $(-0.683,0.042)$ & -1.73 & .083 \\
\hline & & $2016-2015$ & $0.95(21.74)$ & $(0.572,1.327)$ & 4.93 & $<.001$ \\
\hline & & $2019-2018$ & $-1.72(62.91)$ & $(-2.815,-0.629)$ & -3.09 & .002 \\
\hline & Return on Assets (\%) & $2018-2017$ & $-0.20(61.24)$ & $(-1.263,0.866)$ & -0.37 & .715 \\
\hline & & $2017-2016$ & $11.44(64.03)$ & $(10.328,12.553)$ & 20.16 & $<.001$ \\
\hline & & $2016-2015$ & $15.86(84.59)$ & $(14.394,17.333)$ & 21.16 & $<.001$ \\
\hline
\end{tabular}

\section{Relationship between liquidity and economic} profitability

To accomplish the last goal, it was done a multiple linear regression to better understand the relationship between liquidity and economic profitability. To test the relationship between both ratios, the model presents the economic profitability of 2019 as a dependent variable and the liquidity ratios for the years between 2015 and 2019 as explanatory variables. Both for hotels and restaurants, the explanatory power of the variation in economic profitability through liquidity was almost null since for hotels the $\mathrm{R}^{2}$ was 0.002 and for restaurants was 0.005 . For hotels, the model is statistically insignificant, which implies that there is no significant relationship between the economic profitability of 2019 and liquidity ratios from 2015 to 2019. Considering restaurants, the model is statistically significant, indicating a significant relationship between the economic profitability of 2019 and the predictors, 2015 and 2019 liquidity. However, only $0.05 \%$ of the variance of ROA 2019 is explained by the variance in liquidity ratios. The results obtained demonstrate that in the case of Portuguese hotels and restaurants owned by SMCs, there is no clear relationship between the companies' liquidity and economic profitability.
Table 6. Regression of economic profitability ratio on liquidity ratio

\begin{tabular}{|c|c|c|c|c|c|c|}
\hline Sector & \multicolumn{3}{|c|}{ Hotels } & \multicolumn{3}{c|}{ Restaurants } \\
\hline & Coefficient & $t$ & Sig. & Coefficient & $t$ & Sig. \\
\hline (Constant) & 1.573 & 4.819 & $<.001$ & -9.451 & -14.169 & $<.001$ \\
\hline Liquidity 2015 & 0 & -0.015 & .988 & -0.141 & -2.289 & .022 \\
\hline Liquidity 2016 & 0 & -0.351 & .726 & -0.003 & -0.089 & .929 \\
\hline Liquidity 2017 & -0.006 & -2.177 & .030 & -0.032 & -0.378 & .706 \\
\hline Liquidity 2018 & 0 & 0.049 & .961 & 0.012 & 0.137 & .891 \\
\hline Liquidity 2019 & 0.002 & 0.626 & .531 & 0.576 & 6.708 & $<.001$ \\
\hline R-squared & 0.002 & & & 0.005 & & \\
\hline Adj. R-squared & 0.000 & & & 0.005 & & \\
\hline F-statistic & 1.048 & & & 13.030 & & \\
\hline Prob(F-statistic) & .388 & & & $<.001$ & & \\
\hline Depend & & & & & & \\
\hline
\end{tabular}

Dependent Variable: Economic profitability ROA 2019 


\section{DISCUSSION AND CONCLUSIONS}

As tourism is an important source of income for all countries in Europe, and in particular for Portugal (FFMS, 2020a); FFMS, 2020b; FFMS, 2020c; Turismo de Portugal, 2021a); Turismo de Portugal, 2021b); Turismo de Portugal, 2021c); INE, 2019), it is important to understand if the companies in this sector have proper management. This knowledge is of paramount importance since the whole sector had a severe setback with the global pandemic due to the COVID-19, and it is urgent to use the best management tools to recover and maintain companies in the long term. Previous literature agrees that most of the companies in this sector are SMCs, as in the rest of the Portuguese entrepreneurial sector. SMCs use to have a short-term management style, giving priority to management by liquidity, rather than to economic profitability (De Vries et al., 2009; Lakatos, 2020). The financial ratios, based on the financial information of the companies, allow an in-depth analysis of both the companies and the sector and allow the assessment of the situation of the sector in terms of short, medium- and long-term management (Bordeianu and Radu, 2020; Reyes-Ruiz and Hernández-Hernández, 2020; Rondós-Casas et al., 2018). In this study, the current liquidity ratio (Bordeianu and Radu, 2020) was used for the analysis of short-term and ROA (Bordeianu and Radu, 2020) from a medium- and long-term perspective.

The study had the main research question and four goals to better answer this research question. Concerning the first goal, to analyze the evolution of the liquidity of hotels and restaurants in the last 5 years before COVID-19, there were found differences in the hotels and restaurants groups, as restaurants are more stable, yet with lesser liquidity than hotels. The second goal, to analyze the evolution of the economic profitability of hotels and restaurants in the last 5 years before COVID-19, there were also found differences in both sectors. Hotels tend to have more stable profitability, yet very low over the years, as restaurants seem to have a highly variable economic profitability. Concerning the third goal, to analyze the overall financial performance of SMCs hotels and restaurants, findings show that hotels have high liquidity, but restaurants only have a moderate one. These findings are consistent with the study of Turegun (2019). As for the ROA, both hotels and restaurants have a low ratio. This result is not in line with the study of Turegun (2019), which concluded that restaurants have higher profitability than hotels. However, it can be due to the use of different ratios to measure the economic profitability, as that study used the ROE ratio, and the present study used the ROA ratio.

Lastly, the fourth goal is to analyze the relationship between liquidity and economic profitability, findings show that there is no relation between those two ratios. This result is consistent with prior literature (Mendoza, 2015).

All those findings allow us to answer the research question: "Does a higher liquidity leads to higher economic profitability, in the hotels and restaurants sector held by SMC?". Findings suggest indeed that even if a company has high liquidity, it does not mean that it has, or will have higher economic profitability. As companies intend to grow and expand their capacity, this fact can be an issue. These findings are also in line with the study of Mendoza (2015).

The contribution of this study is that it is useful not only for a better economic understanding of the behavior of the SMCs managers, but also to alert them that the company's long-term maintenance must be based on a long-term vision, valuing economic profitability, and not just immediate liquidity. Like any study, this one also has some limitations. Despite being on the alert that SMCs managers should not use the liquidity ratio as a predictor of future economic profitability, no new tools are proposed to include future income by the companies. For future research is proposed to find new management tools that go beyond the current limitations. Also, it was possible to verify the existence of many outliers in data from the SABI database, which seriously decreased the sample dimension.

\section{Acknowledgment}

We thank Universidade Europeia, who funded this article.

\section{REFERENCES}

Atrill, P., \& McLaney, E.J. (2019). Accounting and Finance for Non-Specialists, $11^{\text {th }}$ Edition. Pearson Education.

Bhattacharyya, S.S., \& Jagadeesh, K. (2018). Working Capital Management of Micro \& Small Enterprises. Indian Journal of Industrial Relations: Economics \& Social Dev., 54(1), 177-192.

Bordeianu, G.D., \& Radu, F. (2020). Basic Types of Financial Ratios Used to Measure a Company's Performance. Economy Transdisciplinarity Cognition, 23(2), 53-58.

Burja, C., \& Burja, V. (2009). Analysis of companies' economic performance using the profitability rates. European Research Studies Journal, 12(2), 99-110. https://www.um.edu.mt/library/oar//handle/123456789/31862

De Vries, H., Blind, K., Mangelsdorf, A., Verheul, H., \& Van der Zwan, J. (2009). SME access to European standardization. Enabling Small and Medium-sized Enterprises to Achieve Greater Benefit from Standards and from Involvement in Standardization, Rotterdam School of Management, Erasmus University, August 1.

Espert, J.L.C., Romero, F.J.C., \& Tabuenca, A.G. (2012). Size and sector in the efficiency of mergers involving unlisted companies. Tamaño y Sector En La Eficiencia de Las Fusiones Entre Compañías No Cotizadas., 41(153), 51-87. https://doi.org/10.1080/02102412.2012.10779718

Hair, J.F., Black, W.C., Babin, B.J., \& Anderson, R.E. (2014). Multivariate Data Analysis (7th ed.). Pearson New International Edition.

Kamandulienè, A., \& Kulbokas, Ž. (2020). The Assessment of Financial Performance of the Lithuanian Dairy Sector's Listed Companies. Management of Organizations: Systematic Research,83(1) 73-92. https://doi.org/10.1515/mosr-2020-0005

Lakatos, V. (2020). Controlling Tools for Decision-making in Micro, Small, and Medium-sized Enterprises. The Annals of the University of Oradea. Economic Sciences, 1(2), 192-203.

Lima Santos, L., Gomes, C., Malheiros, C., \& Lucas, A. (2021). Impact Factors on Portuguese Hotels' Liquidity. Journal of Risk and Financial Management, 14(4), 144. https://doi.org/10.3390/jrfm14040144 
Lukic, R. (2018). The Analysis of the Operative Profit Margin of Trade Companies in Serbia. Review of International Comparative Management, 19(5), 458-475. https://doi.org/ https://doi.org/ https://doi.org/ https://doi.org/10.24818/RMCI.2018.5.458

Mendoza, R.R. (2015). Financial Performance of Micro, Small, and Medium Enterprises (MSMEs) In the Philippines. The International Journal of Business and Finance Research, 9(4), 67-80.

Mulyadi, D., Sihabudin, \& Sinaga, O. (2020). Analysis of Current Ratio, Net Profit Margin, and Good Corporate Governance against Company Value. Systematic Reviews in Pharmacy, 11(1), 588-600. https://doi.org/10.5530/srp.2020.1.74

Nguyen, V.C., Nguyen, T.N., Le, T.T.O., \& Nguyen, T.T. (2019). Determining the impact of financial performance factors on bankruptcy risk: An empirical study of listed real estate companies in Vietnam. Investment Management \& Financial Innovations, 16(3), 307-318. http://dx.doi.org/10.21511/imfi.16(3).2019.27

Nikolaos, Z., Christos, K., George, T., \& Efstratios, L. (2020). Financial analysis of major retail chains within a turbulent economic environment. Studies in Business \& Economics, 15(3), 208-222. https://doi.org/10.2478/sbe-2020-0054

Papadeas, P., \& Sykianakis, N. (2017). Analysis and Investigation of Financial Statements. Papadea Publications, Athens.

Paulet, E., Parnaudeau, M., \& Abdessemed, T. (2014). The SME struggle for financing: A clampdown in European banks post-crisis. Journal of Business Strategy, 36-36-45. https://doi.org/10.1108/JBS-09-2013-0089

Reyes-Ruiz, G., \& Hernández-Hernández, M. (2020). Fuzzy clustering as a new grouping technique to define the business size of SMEs through their financial information. Journal of Intelligent \& Fuzzy Systems, 1-10. https://doi.org/10.3233/jifs-189184

Rondós-Casas, E., Linares-Mustarós, S., \& Farreras-Noguer, M.À. (2018). Expansion of the current methodology for the study of the short-term liquidity problems in a sector. Intangible Capital, 14(1), 25-34. http://dx.doi.org/10.3926/ic.1085

Sagner, J. (2010). Essentials of working capital management. 55, John Wiley \& Sons.

Turegun, N. (2019). Performance analysis of the restaurant and hotel industry: evidence from Borsa Istanbul. Journal of Economics, Finance and Accounting, 6(3), 115-123. http://doi.org/10.17261/Pressacademia.2019.1110

Van, M.G., Şehribanoğlu, S., \& Van, M.H. (2021). Analysis of the Factors Which Affect Financial Failure and Bankruptcy with Generalized Ordered Logit Model. International Journal of Management Economics and Business, 17(1), 63-78. https://doi.org/10.17130/ijmeb.803957

Verheul, I., Wennekers, S., Audretsch, D., \& Thurik, R. (2001). An Eclectic Theory of Entrepreneurship: Policies, Institutions, and Culture. Tinbergen Institute Discussion Papers 01-030/3. Tinbergen Institute. http://hdl.handle.net/10419/85867

*** Bureau Van Dijk. (2021). Sabi, Informacion Financiera de empresas españolas y portuguesas. https://www.bvdinfo.com

*** FFMS. (2020a). Balança de viagens e turismo em \% do PIB. PORDATA - Estatísticas, gráficos e indicadores de Municípios, Portugal e Europa. Retrieved April 2021. http://www.pordata.pt

*** FFMS. (2020b). Capacidade dos alojamentos turísticos: Total e por tipo de estabelecimento. PORDATA - Estatísticas, gráficos e indicadores de Municípios, Portugal e Europa. Retrieved April 2021. http://www.pordata.pt

*** FFMS. (2020c). Despesa média diária por turista: Total, por motivo principal e por destino da viagem. PORDATA - Estatísticas, gráficos e indicadores de Municípios, Portugal e Europa. Retrieved April 2021.http://www.pordata.pt

*** FFMS. (2021). Pequenas e Médias Empresas (PME). PORDATA - Estatísticas, gráficos e indicadores de Municípios, Portugal e Europa. Retrieved April 2021. http://www.pordata.pt

*** INE. (2019). Anuário Estatístico de Portugal: 2019. Lisboa: Instituto Nacional de Estatística. https://www.ine.pt/xurl/pub/444301590

*** Turismo de Portugal. (2020). TravelBI - Turismo em Números. https://travelbi.turismodeportugal.pt/pt-pt/Paginas/PowerBI/ Sustentabilidade/emprego-no-turismo-por-sexo.aspx

*** Turismo de Portugal. (2021a). TravelBI - Empreendimentos turísticos-Suspensão de atividade. https://travelbi.turismo deportugal.pt/pt-pt/Paginas/PowerBI/empreendimentos-suspensao-atividade-covid19.aspx

*** Turismo de Portugal. (2021b). TravelBI - População Empregada | 2020. https://travelbi.turismodeportugal.pt/pt-pt/Paginas/Popula $\%$ C3\%A7\%C3\%A3o-Empregada--2020.aspx

*** Turismo de Portugal. (2021c). TravelBI - Turismo em Números | dezembro 2020 (com receitas turísticas). https://travelbi.turismodeportugal.pt/pt-pt/Paginas/turismo-em-numeros-2020.aspx

Article history: Received: 19.10.2021 Revised: 29.12.2021 Accepted: 31.01.2022 Available online: 23.02.2022 